\title{
GUERRA GUASÚ : UM RETORNO ÀS ABORDAGENS JORNALÍSTICAS NOS PORTAIS MAIS ACESSADOS DA TRÍPLICE ALIANÇA E DO PARAGUAI
}

\author{
HELTON COSTA \\ UNIVERSIDADE TUIUTI DO PARANÁ \\ CURITIBA, PARANÁ, BRASIL \\ E-MAIL: HELTON.COSTA@SECAL.EDU.BR
}


GUERRA GUASÚ 1 : UM RETORNO ÀS ABORDAGENS JORNALÍSTICAS NOS PORTAIS MAIS ACESSADOS DA TRÍPLICE ALIANÇA E DO PARAGUAI

Resumo: o presente artigo tem como objetivo analisar como o assunto "Guerra do Paraguai" é lembrado em notícias veiculadas entre 09 de junho de $2014 \mathrm{e}$ 30 agosto de 2015, nos maiores portais de notícia dos quatro países envolvidos no conflito entre 1864-70. Os portais G1, El País, La Nacíon e ABC Color. Ao final é possível ter um quadro com a importância que os jornais deram ao assunto. Palavras-chave: Guerra Paraguai; jornalismo; enquadramento;América Latina

\section{GUASÚ GUERRA: UN RETORNO A LOS ENFOQUES PERIODÍSTICOS EN LOS PORTALES MÁS CONSULTADOS DE LA TRIPLE ALIANZA Y PARAGUAY}

Resumen: Este artículo tiene como objetivo analizar el tema "Guerra del Paraguay" es recordado en los informes publicados entre 09 de junio 2014 y 30 de agosto de 2015, en los mayores portales de noticias de los cuatro países involucrados en el conflicto entre 1864-70; Portales G1, El País, La Nación y $A B C$ color. Al final se puede tener una idea de la importancia que los periódicos han dado al tema. Palabras clave: Guerra de Paraguay; periodismo; marco; América Latina

\section{GUASÚ WAR: A RETURN TO THE JOURNALISTIC APPROACHES IN MOST ACCESSED PORTALS OF THE TRIPLE ALLIANCE AND PARA- GUAY}

Abstract: this article aims to analyze the subject "Paraguayan War" is remembered in reports published between June 9, 2014 and August 30, 2015, in the largest news portals of the four countries involved in the conflict between 1864-70. G1 portals, El País, La Nacion and ABC Color. At the end it can have a picture with the importance that newspapers have given the issue. Keywords: War Paraguay; journalism; framework; Latin America

1 Do guarani, significa "grande”. Guerra Guasu ou Guerra Grande são também nomes da Guerra do Paraguai 


\section{INTRODUÇÃO}

Entre os anos de 1864-70, Brasil, Argentina e Uruguai travaram uma guerra contra o Paraguai que custou de 370 mil a 500 mil vidas entre civis e militares. De um lado, a Tríplice Aliança, formada pelos três primeiros e do outro um país sozinho, que ao final de quase seis anos de conflito tornou-se um dos mais pobres das Américas.

Hoje a história é contada em livros com diferentes versões, algumas favoráveis aos vencedores e outras que retratam um Paraguai perdedor e vítima de barbáries dos aliados.

Cento e cinqüenta anos depois, muitas dessas versões estão presentes no campo social e o Jornalismo, por recortar e divulgar parte desse pensamento, acaba por trazer representações que também se aliam com essas mesmas visões históricas.

Nesse trabalho o objetivo é investigar como o assunto foi tratado nos portais de notícia mais acessados dos quatro países envolvidos e a partir daí concluir como a Guerra, encerrada há 15 décadas, tem sido lembrada para os usuários a partir de práticas jornalísticas.

Para chegar à esse objetivo, a primeira parte do artigo trata sobre o que foi a guerra. Em seguida trata-se do conceito de notícia adotado no trabaIho, faz-se um breve resumo sobre enquadramento e dos veículos de comunicação estudados. Em seguida há a apresentação metodológica e a análise dos textos noticiosos.

\section{GUERRA DO PARAGUAI}

Após a independência do Paraguai em 1811, assumiu o poder no país, José Gaspar Rodríguez Francia. Sem grupos que pudessem lhe ameaçar (latifundiários, comerciantes ou traficantes de escravos), Francia governou o país até a morte em 1840.

Após a morte de Francia, foram eleitos governantes comuns para comandar a República: o cônsul militar Mariano Roque Alonso e o civil Carlos Antonio López. Os dois se revezaram no poder até 1844. Um novo Congresso decidiu por eleger Carlos Antônio López o primeiro presidente do Paraguai livre e Mariano se retirou da vida pública, morando em sua fazenda na localidade de "Ybytymí", onde viveu até os últimos anos de vida em 1853. 
Guerra Guasú : um retorno às abordagens jornalísticas nos portais mais acessados da Tríplice Aliança e do Paraguai

(MUNICIPALIDAD DE MARIANO ROQUE ALONSO, $2012^{11}$ )

Carlos Antônio López foi o pai de Solano López, que assumiu o poder em 1862. A relação de poder existente entre Governo e povo nessa época podia ser vista com maior clareza em Assunção, uma vez que no interior os avanços eram quase inexistentes. Ter um presidente não significava a existência de uma democracia. (CAMPOS, $2011^{12}$ )

Com a organização do Estado nesses moldes, começaram a aparecer com mais frequência os latifúndios estatais, antes reduzidos a sistemas menos abrangentes com um campesinato de subsistência. O Estado começou a "escriturar" a terra como sendo sua, em um processo de estatização que mudou mais uma vez a relação social que vinha estabelecida e mantida desde os primeiros anos pós-jesuítas no Paraguai. (POMER, 1980, p.141)

Com a morte de Carlos, o filho Solano assumiu e deu continuidade nas medidas que o pai já vinha adotando. “(...) El Estado paraguayo se había transformado en un feudo particular de la familia López” (PAGNI, 2009³). Porém, o segundo Lopez no poder entraria para a história como o presidente que levou o país às armas, chamada no Brasil de "Guerra do Paraguai" e em outros países de "Guerra de La Tríple Alianza”. (ARAKAKI, 2009, p.30).

O saldo da guerra foi pior para o Paraguai, pois, há autores que dizem que entre 90 e 95\% da população masculina do Paraguai simplesmente deixou de existir depois da guerra. A agricultura perdeu braços e a economia do país ficou debilitada. Porém, outra corrente fixa esse número entre 15 e 20\% da população geral do país, na época estimada em 500 mil habitantes. Pelo Brasil dos cerca de 160 mil combatentes participaram da guerra, 50 mil morreram ou tornaram-se inválidos. Os escravos, que compunham até $30 \%$ dos batalhões mandados para a guerra, só foram libertados em 1888, 18 anos após o fim do conflito, mesmo tendo lutado em uma guerra que não era deles. Dos 5.600 soldados uruguaios, vindos das estâncias dos grandes fazendeiros, estima-se que 3.100 tenham tombado nos campos paraguaios e entre os argentinos morreram 18 mil das tropas de 30 mil soldados combatentes. (MS JÁ, 2011 ${ }^{14}$ )

11 Disponível em http://municipalidaddemarianoroquealonso.gov.py/historia.html. Acesso em 08 de julho de 2014

12 Disponível em http://www.portalguarani.com/obras_autores_detalles.php?id_ obras=14217. Acesso em 13 de junho de 2014

13 Disponível em http://migre.me/6d5kH. Acesso em 13 de julho de 2014.

14 MS JÁ. Disponível em http://www.msja.com.br/noticias/cidades/voce-sabe-o-que- 
Nesse trabalho, a Guerra do Paraguai é entendida como um desdobramento de disputas territoriais e ideológicas travadas pelos quatro países envolvidos, onde o Brasil exercia grande influência junto aos governos de Uruguai e Argentina e onde o Paraguai também queria participar como ator principal dentro desse quadro. (DORATIOTTO, 2002)

\subsection{GUERRA DO PARAGUAI: 1864-1870}

Na época da Guerra do Paraguai, grupos rivais políticos disputavam o poder central na República do Uruguai e também na Argentina. Ambos os grupos da situação tinham apoio brasileiro, que desde a década anterior vinha defendendo seus interesses na região pela força das armas. A situação piorou a partir de 1862, quando opositores dos governos argentino e uruguaio ameaçaram se instalar como mandatários das Repúblicas. (SALLES, 1990, p.49-53)

Também em 1862 a Argentina foi reunificada em torno da liderança de Bartolomé Mitre sendo apoiado por Venâncio Flores - líder colorado que disputava o poder no Uruguai contra os blancos. Mitre participava da facção política que tinha interesses na unidade Argentina em torno de Buenos Aires enquanto Justo José Urquiza era líder da Confederação argentina composta pelas prósperas províncias de Entrerrios e Corrientes. Ainda assim restaram estas províncias que faziam oposição a Buenos Aires e com ligações com o Paraguai e o governo Blanco no Uruguai. Ligações que não se confirmariam com o desencadear da guerra. Os dois blocos políticos estavam assim compostos: de um lado Solano López alinhado com os blancos uruguaios e os federalistas na Argentina, liderados por Urquiza. Do outro lado estavam Brasil e Argentina juntamente com os colorados do Uruguai. Rio de Janeiro e Buenos Aires negociavam para dividir a hegemonia na região (TORAL, 2001, p.52 in LAVARDA, 2009, p.24)

Em 1864, após uma série de intervenções para conter o conflito no Uruguai entre os grupos que disputavam o poder, o Brasil decidiu por mandar tropas e invadir de vez o país vizinho para acabar com as contendas. Para isso usaria a força. Episódio que marca essa época é o bombardeio de Paysandu, quando a cidade foi castigada por dias pela esquadra brasileira, que após solicitar a rendição de tropas dos blancos e ver negada essa possibili-

-significa-nhandipa-o-ms-ja-explica-confira. Acesso em 08/07/2014. 
Guerra Guasú : um retorno às abordagens jornalísticas nos portais mais acessados da Tríplice Aliança e do Paraguai

dade, não hesitou em disparar contra o povoado que tinha como líder Leandro Gomez. Em seguida tropas brasileiras chegaram à Mointividéu. (GUIMARÃES, 2000, p.118)

Os paraguaios então pediram autorização para que tropas de Lopez atravessassem o solo argentino para socorrer os aliados do presidente do Paraguai. A Argentina negou, mas, autorizou que tropas brasileiras se deslocassem por seu território.

A provocação foi entendida como ato de guerra e em um primeiro momento o Paraguai foi quem tomou a iniciativa de combate. Aprisionou o navio Marques de Olinda que transportava o governador de Mato Grosso, Frederico Carneiro de Campos, que subia pelo Rio Paraguai rumo à Cuiabá e invadiu o atual território do Mato Grosso do Sul, na época, apenas Mato Grosso. (SALES, 2007, p.26-31)

Duas colunas paraguaias entraram no Estado por Corumbá rumo à Coxim e pela Colônia Militar dos Dourados (atual município de Antônio João, nome do oficial que comandava a colônia e que foi morto com mais $12 \mathrm{com}$ panheiros). (CREMONESE-ADAMO, 2010, p.83-86). Em outra frente, descendo por Corrientes na Argentina os paraguaios chegaram à Uruguaiana no Rio Grande do Sul.

É preciso ressaltar ainda a assinatura do Tratado da Tríplice Aliança, que os paraguaios ainda hoje defendem como sendo secreto (porque não foi divulgado imediatamente após sua assinatura e porque é contestada a validade das assinaturas nele presente). "Explicando melhor, o acordo foi implacável com o Paraguai e seus termos não foram submetidos ao crivo da opinião pública e nem da imprensa”. (LAVARDA, 2009, p.31)

Após a Batalha do Riachuelo, quando a Marinha brasileira se impôs sobre a paraguaia, a guerra pendeu de vez aos aliados. Outro episódio desse tempo é a rendição de Uruguaiana, quando as tropas lá instaladas sem viram cercadas pelos brasileiros e se renderam. (LAVARDA, 2009, p.31-32)

Logo, os paraguaios se viram obrigados a recuar de seu avanço em solo brasileiro e argentino. Começava a segunda fase da guerra, com uma defensiva que só terminaria em 1869 com a queda de Assunção, iniciada com a invasão aliada ao território paraguaio a partir da ilha de Itapirú. (VAZ, 2011, p. 32)

Seguiram-se nos meses seguintes as batalhas de Estero Bellaco, Tuiuti (maior batalha campal da guerra, com cerca de 56 mil soldados envolvidos), Boqueirão, Sauce, Curuzú, Curupayti (vencida pelos paraguaios) e Humaitá, 
onde a guerra parou por conta dos brasileiros não conseguirem subir o Rio Paraguai, detidos por seus defensores. (RESTIER, 2011, p.34)

Quando os brasileiros finalmente ultrapassaram a fortaleza, em fevereiro de 1868, o avanço por água e terra se tornou possível rumo à Assunção. A infantaria, cavalaria, engenharia e artilharia se deslocaram e em meio à essa subida e foram travadas as batalhas de Itororó, Avaí e Lomas Valentinas. Por muito pouco os aliados não perderam as batalhas, mas, conseguiram a vitória da série que ficou conhecida como "dezembrada”. (LAVARDA, 2009, p.51)

Uma vez tomada Assunção, a terceira fase teve início: a caçada à Lopez, que ficou a cargo do genro do imperador Dom Pedro II, Conde D'Eu. O que restou do exército paraguaio, uns poucos milhares de soldados, se uniu à crianças e velhos sob a ordem de Solano Lopez para tentar derrotar as tropas aliadas.

É desta fase que são as memórias mais traumáticas do conflito, como a batalha de Acosta Nu (Campo Grande), onde Lopez em retirada deixou crianças e idosos para conter os brasileiros que vinham em seu encalço. Os paraguaios, atualmente, lembram essa data como o "Dia de lo Niño", de tão forte que a memória do massacre ainda persiste. Acusam os brasileiros de atrocidades, ao mesmo tempo que tem o episódio como exemplo de valentia nacional, sem se dar conta que como manobra militar, a fuga de Lopez é também um ato de desespero para salvar a própria vida às custas de um exército infantil, uma escaramuça que custou a vida dos jovens enquanto Ihe dava tempo para escapar.

Batalhas menores, encontros entre grupos de combate e guerrilhas foram usadas por Lopez para que esse fugisse rumo às cordilheiras de Cerro Corá, onde morreu ao tentar fugir mais uma vez, ao atravessar o riacho Aquidaban.

\section{RELAÇÃO BRASIL/PARAGUAI NO PÓS-GUERRA ATÉ OS DIAS}

\section{ATUAIS}

Após o final da guerra, os exércitos não eram mais necessários e entraram em cena os acordos diplomáticos para fazer com que os países vencedores consiguissem impor suas formas de governo. "La guerra cambia de forma y estrago. Desaparecen los ejércitos y las masas combatientes y le sucede una lucha singular entre los hombres elegidos que desempeñan las 
Guerra Guasú : um retorno às abordagens jornalísticas nos portais mais acessados da Tríplice Aliança e do Paraguai

altas funciones de gobierno". (CÁRCANO, 1941, vol. l, p. 363).

Segundo Sales (2007, p.03) as mudanças no Paraguai não se deram de uma hora para outra e o novo governo colocado pelos brasileiros deveria unir favoráveis à Lopez e novos pensamentos, que modo que o sistema de governo fosse capaz de reerguer o país, sem braços para o trabalho, já que boa parte da população masculina tinha sido morta durante os quase seis anos de batalhas.

Na disputa pelo governo provisório paraguaio se formaram dois grupos políticos: os bareiristas, liderados por Cándido Bareiro, primo de Solano López e ex-representante do governo lopizta na Europa, que somou as forças dos conservadores paraguaios; e os decouistas, liderados por Juan Francisco Decoud, candidato reformista, com ideais liberais. Paranhos realizou, então, uma reunião em Assunção com representantes dos dois círculos políticos, expondo que seria necessário que o novo governo paraguaio concordasse com os termos do Tratado de $1^{\circ}$ de Maio de 1865, para ter o apoio do Rio de Janeiro. (SALES, 2007, p.03)

O Brasil entrou em cena para intermediar o entendimento entre os dois setores divergentes, isso porque os "decouistas" solicitaram mais tempo para um exame detalhado sobre as perdas territoriais paraguaias.

$\mathrm{Na}$ falta de um acordo que satisfizesse as duas partes, Paranhos solicitou a indicação de quatro pessoas do cada grupo, e se não concordassem, o Brasil instalaria um governo militar no país. (SALES, 2007, p.03)

Entre os bareiristas foram indicados Félix Egusquiza, ex-representante de Lópes em Buenos Aires, e Bernardo Valiente; entre os decouistas foram indicados Carlos Loizaga e o próprio Juan Francisco Decoud, que veio a desistir de participar da comissão, indicando para seu lugar José Díaz Bedoya. Outro que se recusou a participar da comissão foi Loizaga, que alegou ser inimigo de Egusquiza. A comissão acabou por ser formada por apenas três membros. (SALES, 2007, p.03)

López ainda não havia sido morto, o que só ocorreria em 1870, quando os paraguaios já estavam sendo obrigados a aceitar alternativas brasileiras. Em 15 de agosto de 1869, foi estabelecida uma junta dos favoráveis ao Brasil para governar o país, desde que não servissem mais López e colaborassem para a vitória total brasileira. Argentina e Uruguai também queriam influenciar o governo do Paraguai, fato este que se intensificou após a morte de 
López em março de 1870. (SALES, 2007, p.05)

O acordo de 1871 decretava a paz definitiva e deixava a questão dos limites territoriais para os anos seguintes. O Brasil influenciou diretamente a eleição de presidentes no Paraguai até 1889 , quando a monarquia foi substituída pela República. (SALES, 2007, p.06). Após os dois primeiros mandados pós-retirada do Brasil, ocorreram no Paraguai até o ano de 1912, sete golpes de Estado. O primeiro a cumprir um mandado inteiro no cargo de presidente desde 1870 foi Eduardo Schaerer. (CHIAVENATO, 1980, p. 30)

Até 1939 mais quatro golpes de Estado foram registrados e até 1954 mais seis mandatos foram marcados por golpes ou renúncias. De 1954 à 1989 se instalaria no poder o ditador Alfredo Stroessner Matiauda, que só saiu do poder após outro golpe militar. (CHIAVENATO, 1980, p. 76). Em 1993 foi eleito o primeiro presidente por voto direto no país desde 1811 (Juan Carlos Wasmosy Monti). Após ele, Raúl Cubas Grau, assumiu em 1998 e renunciou 1999, acusado de envolvimento no assassinato do próprio vice. Depois deles vieram Luis Ángel González Macchi (1999), Nicanor Duarte Frutos (2003), Fernando Lugo (2008).

Essa sucessão de golpes que teve início na Guerra do Paraguai e foi se arrastando ao longo do século XX e do XXI é uma demonstração da fragilidade da democracia no país, que nos poucos momentos que teve de estabilidade política foi porque estava em uma Ditadura. Dentro da democracia propriamente dita, meios legais podem ser manipulados para que o grupo hegemônico ainda que derrotado pelo voto, como no caso Lugo, retorne ao poder por brechas legais da própria Constituição. No caso Lugo, por exemplo, retornaram ao poder políticos que faziam parte exatamente do governo que o ex-bispo católico havia substituído.

\section{NOTÍCIA}

A notícia é entendida neste trabalho como o produto que resulta do fazer jornalístico, inserido numa cadeia produtiva da informação, como lembra Sousa (2004). O autor defende também que "qualquer teoria do jornalismo deve esforçar-se por delimitar o conceito de notícia”, o que por si só justifica a necessidade da apresentação deste conceito, atrelado ao fato de que as notícias são recortes do real. (SOUSA, 2004, p.02) 
Guerra Guasú : um retorno às abordagens jornalísticas nos portais mais acessados da Tríplice Aliança e do Paraguai

\subsection{Da noticiabilidade dos fatos}

Esse recorte do real precisa de critérios que façam um assunto merecer mais visibilidade que outro. Trabalhamos assim, com o conceito "critérios de noticiabilidade", que, na descrição de Traquina (2008), são valores que os membros da tribo jornalística partilham como "conjuntos de critérios e operações que fornecem a aptidão de merecer um tratamento jornalístico, isto é, possuir um valor como notícia". (TRAQUINA, 2008, p.63).

Optamos pelo conceito de Traquina (2008) para conceituar o que é noticiável, por entender que a notícia não é simples espelho da realidade e sim uma série de fatores como as rotinas, que passam pelo ambiente de trabaIho e vão até o grau de formação e conhecimento de mundo do jornalista. Dentro desse contexto, os critérios de noticiabilidade seriam importantes para guiar alguns dos comportamentos que nortearão a produção do conteúdo jornalístico.

\subsection{Valores notícias}

Valores notícias seriam mapas que norteiam a percepção do jornalista, mas não um manual que não possa ser modificado. Autores os descrevem como pontos que influenciariam o agendamento noticioso dentro do ponto de vista do jornalista, tido como agente principal do mecanismo de escolha do que é noticiável ou não.

Traquina (2008) por sua vez, identifica a relevância, a novidade e o tempo como três valores notícia. (TRAQUINA, 2008, p.81) Traquina (2008) também chama a atenção para fatores como: amplificação, relevância, personalização, dramatização e consonância (TRAQUINA, 2008, p.91-3)

Em seguida, Traquina (2008.) cita mais dois grupos que seriam levados em consideração para a produção de notícias. Seriam eles, os critérios substantivos e contextuais. (WOLF, 1987 em Traquina, 2008, p.78)

Os contextuais diriam respeito ao contexto em que a notícia é proibida. Como valores substantivos, Traquina aponta a notoriedade do personagem da eventual notícia, a proximidade em termos culturais e geográficos, a relevância do assunto, a novidade da informação e o tempo que poderá manter-se em destaque. 
Ainda tratando desses ditos valores de seleção, Traquina chama a atenção para a Notabilidade (inversão, o contrário do normal), Inesperado (aquilo que surpreende a expectativa da comunidade jornalística), Conflito ou controvérsia (violência física ou simbólica entre partes concorrentes) e Infração (violação ou transgressão de regras), Escândalo (dá ao jornalista o papel de "cão de guarda" das instituições democráticas). (TRAQUINA, 2008, p.83-85)

Após apresentados esses pontos, é possível dizer que esse trabalho entende a notícia como recorte construído de uma realidade, com valores que tornam algo merecedor de ser tornado público em um meio de comunicação e que esse "algo" perpassa por critérios substantivos e contextuais, mediados por um agente que o divulga.

\section{OS JORNAIS}

No Brasil, o site analisado foi o G1, que está no ar desde 18 de setembro de 2006. É um produto das Organizações Globo e ocupa a $6^{a}$ posição no ranking do medidor de acessos Alexa.com. Vem buscando atualizar-se ano após ano. Quando comemorou os quatro anos no ar, fez questão em deixar claro esse fato.

De 2006 para cá, o portal passou por mudanças de visual e de conteúdo. Foi ampliada a cobertura de temas como carros, concursos e games e foi criada uma seção de jornalismo colaborativo, o VC no G1. Na parte gráfica, fizemos duas grandes reformas, em 2007 e em 2010. Nos dois casos, o objetivo geral foi facilitar a navegação e expor de modo mais apropriado o vasto conteúdo que temos. $\left(\mathrm{G} 1,2010^{15}\right)$

Outro site analisado será o "La Nácion" (Argentina) (www.lanacion.com. ar), diário com quase de 140 anos de existência. Segundo o medidor Alexa. com é o mais acessado do país em se tratando de jornalismo, ocupando a $8^{a}$ posição no ranking de cliques da ferramenta da Amazon.com. O diário só fica atrás de sites de entretenimento e redes sociais internacionais, mas, 
Guerra Guasú : um retorno às abordagens jornalísticas nos portais mais acessados da Tríplice Aliança e do Paraguai

entre os veículos de informação é o mais acessado. (Disponível em http:// www.alexa.com/siteinfo/lanacion.com.ar)

El 4 de enero de 1870 salieron a la calle los primeros 1.000 ejemplares de uno de los diarios más antiguos de la Argentina. Bartolomé Mitre, quien en ese entonces ya había sido gobernador de la provincia de Buenos Aires, presidente de la República y comandante en jefe de las tropas argentinas en la guerra contra el Paraguay, decidió retomar su vocación juvenil de periodista y poner en marcha el diario La Nación como su director gerente. (BERGER, 2003, p.120)

A história do site La Nácion começa em 2001, quando o grupo após passar por um período tumultuado na administração da empresa resolve migrar conteúdo também para a Internet, até então uma aposta de sucesso para o jornalismo e novidade para investigadores em comunicação. (BERGER, 2003, p.121)

Já o $A B C$ Color (www.abc.com.py) do Paraguai nasce em 08 de agosto de 1967, durante a ditadura de Alfredo Strossner. Como o jornal começou a fazer críticas ao regime, em 1984 foi fechado por tempo indeterminado, só voltando a circular cinco anos depois, com o final da ditadura no país. ( $A B C$ Digital, 2008)

Em 1996 nascia o ABC Color Digital, site de notícias que hoje ocupa o $5^{\circ}$ lugar entre os sites mais acessados do Paraguai e o primeiro lugar entre os sites de notícia. Um dos diferenciais do site é que ele traz artigos em espanhol e em idioma guarani, a segunda língua do país vizinho ( $A B C$ Digital, 2008).

No Uruguai o site estudado será o El País (www.elpais.com.uy), fundado em 1918 e em 1996 aderiu à era digital. Hoje é um dos mais acessados do Uruguai, ocupando a 6 a posição no ranking geral do Alexa e sendo o primeiro na referência de jornalismo.

El diario El País, fundado en 1918, esta en la web desde 1996. Comenzó tímidamente, en una sección más cercana físicamente a la administración que a la sala de redacción, hasta llegar hoy a ser un portal con siete servidores, uno de ellos -el adserver- capaz de segmentar y distribuir la publicidad a la medida de cada anunciante y según el país desde el cual se acceda. (GORDANO, 2006, p.03) 


\section{MÉTODO DE ANÁLISE}

As notícias foram recuperadas nos buscadores dos arquivos dos sites. Foram utilizadas as seguintes palavras-chave: Guerra Guasu, Guerra Grande, Guerra Del 70, Guerra Paraguai, Guerra Paraguay, Triple Alianza e Tríplice Aliança. Foram encontrados 14 registros no G1, 21 no La Nación, 212 no ABC Color e 25 no El País.

As notícias foram então separadas em:

Diretamente relacionadas à guerra: que tratam sobre a guerra, seus desdobramentos/conseqüências ou que relembram combates e datas comemorativas/históricas sobre o conflito;

Indiretamente relacionadas à guerra: nomes de ruas, pontos de referência, nomes de espetáculo culturais, de cidades, vilarejos ou pessoas;

Propagandas literárias: textos sobre obras que têm como tema a guerra, editada por jornais dos países. Por tratarem diretamente do tema da guerra, essas publicações também estão inseridas dentro dos temas "Diretamente relacionados à guerra".

Em seguida, houve nova análise, dessa vez quanto ao protagonismo, onde foram classificadas em versão "Paraguai vítima", que aponta os aliados como agressores, versão "Paraguai culpado", que aponta o Paraguai como causador do conflito e versão "neutra", que não se refere à nenhuma das duas anteriores.

Da mesma forma as "Propagandas literárias" também foram classificadas em versão "Paraguai vítima”, versão "Paraguai culpado" e versão "neutra".

\section{RESULTADOS DAS ANÁLISES}

No site argentino foram encontradas 21 notícias com as palavras-chave buscadas. A maioria delas não citava diretamente o conflito, se baseavam em cartas de leitores ou notas da redação e não se apresentavam como textos jornalísticos. A questão energética de usinas conjuntas entre Paraguai e Argentina, com reclamações do primeiro, também era assunto recorrente na publicação. Somente quatro notícias das 21 relembravam o conflito de forma direta.

No jornal brasileiro, o número de notícias foi de 14, porém nove falavam sobre eventos da guerra. Em todas elas apareciam reencenações e tombamentos de patrimônio, principalmente no Rio Grande do Sul e no Mato Gros- 
Guerra Guasú : um retorno às abordagens jornalísticas nos portais mais acessados da Tríplice Aliança e do Paraguai

so do Sul, estados que foram invadidos por colunas do Exército paraguaio nos primeiros meses de guerra.

Já no jornal do Uruguai apareceram 25 resultados, sendo 13 citações indiretas e 12 diretas. A data comemorativa dos 150 anos de início do conflito pode ter sido o fator motivador desse equilíbrio entre notícias diretas e indiretas. O que chama a atenção nas indiretas é a utilização dos episódios anteriores ao conflito, com a invasão brasileira ao Uruguai e o bombardeio de Paysandu.

Dentro do estudo, o quadro que mais chamou a atenção mais uma vez foi o caso paraguaio, onde foram encontrados 212 registros, dos quais 95 foram diretamente referentes à guerra. Outros 117 lembravam indiretamente do conflito. Vinte e nove notícias eram "propagandas literárias" e foram inseridas dentro de notícias "diretamente relacionadas à guerra", conforme informado nos procedimentos de análise. O Paraguai aparecia como vítima em todos casos, em nenhuma como culpado.

E assim como aconteceu da primeira vez, o Paraguai e o Uruguai foram os países que mais tiveram notícias veiculadas, justamente o primeiro o país que foi derrotado e o segundo o país que motivou os protestos de Lopez e que o levaram à guerra.

Em um quadro comparativo entre 2013 e 2014 teríamos a seguinte configuração:

\begin{tabular}{|c|c|c|c|}
\hline Jornal & $\begin{array}{l}\text { Número de } \\
\text { notícias } \\
2013 / 2014\end{array}$ & $\begin{array}{l}\text { Número de } \\
\text { notícias 2014/15 }\end{array}$ & $\begin{array}{l}\text { Aumento em } \\
\text { porcentagem }\end{array}$ \\
\hline G1 & 06 & 14 & $233 \%$ \\
\hline La Nacion & 02 & 21 & $1.050 \%$ \\
\hline E1 Pais & 23 & 25 & $108 \%$ \\
\hline ABC Color & 62 & 212 & $341 \%$ \\
\hline
\end{tabular}

Tabela 01: Quadro comparativo entre 2013 e 2014

Nessa pré-análise, é possível dizer ao menos, que em maior ou menor escala, a Guerra do Paraguai ainda é um assunto com noticiabilidade suficiente em todos os países envolvidos, assim como foi no período anterior, em 2013, quando ocorreu a primeira análise. 


\section{CONSIDERAÇÕES FINAIS}

Após a análise das notícias é possível dizer que no Paraguai, por ter sido o país mais afetado pelos combates, por ter sido invadido pelos aliados e por ter perdido boa parte de sua população, principalmente a masculina, continua a evocar a memória do conflito via jornalismo. Contribui para essa análise, o fato da própria guerra ter valores substantivos como notabilidade, inesperado, conflito ou controvérsia, infração e escândalo, por exemplo.

Logo, é possível dizer que o jornalismo é usado como uma ferramenta para tornar pública parte da realidade que o país vive ainda hoje por conta dos conflitos de 150 anos atrás. Um país que ainda se coloca como vítima histórica, inclusive solicitando indenização por um holocausto defendido por seus deputados, encontra no jornalismo uma forma de externar seus pensamentos e tanto é assim que em nenhuma publicação faz "meia culpa" ou assume erros durante a campanha.

O Brasil e em menor escala a Argentina são os maiores vilões. Solano Lopez, que é tido no Brasil como um dos causadores do conflito é visto como herói nacional nas publicações do $A B C$, exceto em uma publicação de um pesquisador argentino o intitula como um dos quatro Cavaleiros do Apocalipse. Transformá-lo em herói é uma reprodução da apropriação do período em que militares e políticos ligados ao antigo regime do ex-presidente se aglutinaram no Partido Colorado e chegaram ao poder, principalmente a partir da década de 30, quando o coronel Rafael Franco governou o país. (ASSUNÇÃO, 2012, p.158)

O terreno vinha sendo preparado desde o pós-guerra por Juan Emiliano O'Leary (1883-1969) e pelo filho mais jovem de Lopez, Enrique Venancio, que após exilado na Europa por vontade própria, retornou ao país para reaver bens que dizia pertencerem à sua família. (ASSUNÇÃO, 2012, p.161-164)

Mais tarde, em 1936, foi terminado o Panteão dos Heróis em Assunção e os restos mortais de Lopez foram levados de Cerro Corá para a capital. Em 1950, o ditador Alfredo Stroessner reivindicou para si os valores lopistas como forma de se legitimar no poder, trabalhando com o "apelo emocional e patriótico". (ASSUNÇÃO, 2012, p.165)

No Paraguai o aumento de notícias foi considerável (343\%) e é como se a cada dois dias os leitores do $A B C$ Color fossem receber algum lembrete sobre a Guerra Guasu, seja em forma de notícia ou de referência geográfica ou temporal que lhes recordasse dos abusos dos países vizinhos contra seus 
Guerra Guasú : um retorno às abordagens jornalísticas nos portais mais acessados da Tríplice Aliança e do Paraguai antepassados.

O Brasil aparece no noticiário da Guerra Guasu como ladrão, saqueador, motivador de um holocausto e injusto, sempre com desdenho e desconfiança. Até mesmo julgamentos populares contra o país foram noticiados e neles os brasileiros foram condenados. Já a guerra e seus generais paraguaios são exemplos para a juventude e para as novas gerações, talvez um resquício da ditadura à qual o país esteve exposto desde 1954, com abertura na década de 90.

No Brasil, o que chama a atenção é que principalmente nos Estados onde a Guerra passou, Rio Grande do Sul e Mato Grosso do Sul, as notícias são mais freqüentes. $O$ que auxiliou no aumento de notícias foi uma série produzida pelo $\mathrm{G} 1$ em conseqüência dos 150 anos de declaração de guerra, lembrada em dezembro em 2014. A máxima valeu também para os outros países. Além desse fator, a visita do Papa Francisco também motivou matérias em todos os países, uma vez o pontífice disse que a Guerra Guasu foi injusta e que as mulheres paraguaias do pós-conflito eram exemplos a serem seguidos.

Se antes as poucas matérias veiculadas no G1 eram algo próximo do que ocorre outros eventos bélicos, pela não lembrança, em 2014 os 150 anos de conflito fizeram a situação mudar.

As visões do $\mathrm{G} 1$ buscaram se afastar dos pontos de vista ufanistas das primeiras análises de militares e ex-combatentes ${ }^{16}$, entendendo a contenda muito mais como resultado de disputas de poder na região do Prata na época.

É preciso destacar também que assim como pode ter acontecido em 2013, outros valores notícias podem ter sobreposto o assunto "Guerra do Paraguai", o que poderia fazer com que o tema ficasse em segundo plano.

No Uruguai, Paysandu e o líder dos contrários aos brasileiros, Leandro Gomez, são assuntos que volta e meia remetem ao conflito no Paraguai. Isso porque, na visão uruguaia, assim como na visão paraguaia, Paysandu foi o estopim do conflito e se o Brasil não tivesse feito intervenção nas terras orientais, não teria havido agitação. Assim como no Brasil, os 150 anos de conflito fizeram a diferença para o aumento de notícias sobre a disputa.

16 Visão essa que depois revisto por uma corrente esquerdista que muito se assemeIha aos autores que vêem o Paraguai como vítima do imperialismo brasileiro e que atualmente aglutina os dois pontos de vista em visões que ao final têm como objetivo trazer uma interpretação menos apaixonada 
Quanto ao comportamento do La Nación da Argentina, que teve o maior crescimento de noticiabilidade sobre o assunto (1.050\%), tal fato se deve exatamente aos dois pontos apontados anteriormente: visita do Papa e 150 de conflito. Somou-se a isso a visita da presidente Cristina Kirchner ao país vizinho, onde tocou no assunto ao defender uma amizade entre as duas nações.

Em 2013 o Brasil apresentava a postura de vencedor, falando sobre suas vitórias. A Argentina se calava; o Uruguai se solidarizava com uma versão paraguaia do país como vítima e o Paraguai assumia essa postura na busca convencer seus leitores dessa posição assumida, tratando como genocídio, infâmia, invasão, latrocínio, entre outros adjetivos que atribuem aos aliados atos de agressão para início do conflito, abusos contra a população e contra prisioneiros.

Em 2014 o quadro não só se manteve como se ampliou e mais que em 2014 o Paraguai colocou-se como vítima de um complô internacional para destruí-lo, onde Solano López foi um herói ao encarar a missão de evitar tal tragédia. Falhou e foi morto em combate, ao tentar fugir de seus perseguidores.

O Brasil continuou a manter-se como o vencedor que não quer falar sobre lados negativos e o Uruguai também se colocou como vítima, enquanto a Argentina assumiu um papel mais neutro, mas ainda assim mais favorável ao Paraguai.

Logo, nesse segundo ano de análise é possível afirmar que de acordo com os números, a Guerra do Paraguai ainda é assunto noticiável e que principalmente nos países fora do Brasil a vitimização é uma tendência. Nos anos posteriores novas análises poderão apontar se essa "tendência" se confirma ou será refutada.

\section{REFERÊNCIAS}

ARAKAKI, S. Dourados: memórias e representações de 1964. Dourados/MS: Editora UEMS, 2008.

ASSUNÇÃO, Moacyr. Nem heróis, nem vilões: curepas, caboclos, cambas, macaquitos e outras revelações da sangrenta Guerra do Paraguai. Rio de Janeiro: Record, 2012.

BERGER, Gabriel. El diario La Nación y la Red Solidaria. Academia, Revista Latino Americana de Administración, 31, Cadea, Bogotá, 2003

Brasil Escola. Disponível em http://www.brasilescola.com/historia-da-america/historia-pa- 
Guerra Guasú : um retorno às abordagens jornalísticas nos portais mais acessados da Tríplice Aliança e do Paraguai

raguai.htm. Acesso em 13 de julho de 2014

CAMPOS, Herib Caballero. Disponível em http://www.portalguarani.com/obras_autores detalles.php?id_obras=14217. Acesso em 13 de julho de 2014

CÁRCANO, R. J. Guerra del Paraguay: acción y reacción de la Triple Alianza. In: DORATIOTO, F. F. M.. Maldita Guerra: nova história da Guerra do Paraguai. São Paulo: Companhia das Letras, 2002, p.465.

CHIAVENATO, J. J. Stroessner: retrato de uma ditadura. São Paulo: Brasiliense, 1980.

CREMONESE-ADAMO, Camila . "Dourados: Terra de Antônio João" - Considerações sobre a construção e incorporação da figura heróica de Antônio João na cidade de Dourados/MS. In: III Simpósio Internacional sobre Religiosidades, Diálogos Culturais e Hibridações, 2009, Campo Grande. III Simpósio Internacional sobre Religiosidades, Diálogos Culturas e Hibridações. Campo Grande: UFMS, 2009. p. 1-6.

Doratioto, Francisco. 2002. Maldita Guerra: nova história da Guerra do Paraguai. São Paulo: Companhia das Letras.

GUIMARÃES, Acyr Vaz. A Guerra do Paraguai: verdades e mentiras. Campo Grande: Instituto Histórico e Geográfico de Mato Grosso do Sul, 2000

LAVARDA, M. T. B. A iconografia da Guerra do Paraguai e o periódico Semana Illustrada (1865-70): um discurso visual. Dissertação apresentada ao Programa de Pós-Graduação em História da Faculdade de Ciências Humanas da Universidade Federal da Grande Dourados, para a obtenção do título de Mestre em História. Dourados, MS, 2009.

MS JÁ. Disponível em http://www.msja.com.br/noticias/cidades/voce-sabe-o-que-significa-nhandipa-o-ms-ja-explica-confira. Acesso em 08/07/2014.

Municipalidad de Mariano Roque Alonso. Disponívél em http://municipalidaddemarianoroquealonso.gov.py/historia.html. Acesso em 13 de julho de 2014

PAGNI, F. La metamorfosis de Francisco Solano López. 2009. Disponível em: <http://migre.me/6d5kH>. Acesso em: 12 jun. 2012.

RASTIER, Renato. Embarcações Blindadas. In Revista de História da Biblioteca Nacional. Ano 6, n70, julho de 2011. p.34-35

SALES, Thiago Rabelo . As relações entre o Brasil e o Paraguai no contexto do pós-guerra (1870-1875). In: XXIV Simpósio Nacional de História - História e multidisciplinaridade: territórios e deslocamentos, 2007, São Leopoldo. XXIV Simpósio Nacional de História - História e multidisciplinaridade: territórios e deslocamentos. São Leopoldo, 2007.

SALLES, Ricardo. Guerra do Paraguai: escravidão e cidadania na formação do exército. Rio de Janeiro: Paz e Terra, 1990.

SOUSA, Jorge Pedro (2004). Construindo uma Teoria Multifactorial da Notícia como uma Teoria do Jornalismo. Biblioteca On-Line de Ciências da Comunicação. Disponivel em http://www.bocc.ubi.pt/pag/sousa-jorge-pedro-multifactorial-jornalismo.pdf. Acesso em 04/09/2012

TORAL, André. Imagens em desordem: a iconografia da Guerra do Paraguai. São Paulo: Humanitas / FFLCH / USP, 2001. 
TRAQUINA, Nelson. Teorias do jornalismo. A tribo jornalística - uma comunidade interpretativa transnacional. Florianópolis: Insular, 2 ed. 2008.

VAS, Braz Batista. Parecia uma Tempestade. In Revista de História da Biblioteca Nacional. Ano 6, n’70, julho de 2011. p.32-33

WOLF, Mauro. Teorias da Comunicação. Lisboa: Editorial Presença, 1994.

www.abc.com.py

www.alexa.com

www.elpais.com.uy

www.lanacion.com.ar

\section{Helton Costa}

Coordenador do Curso de Jornalismo da Secal, de Ponta Grossa/PR. Dr. em Comunicação pela Universidade Tuiuti do Paraná. Tataraneto de ex-combatente baiano da Guerra do PY casado com argentina, de ex-soldados paraguaio casado com brasileira e de ex-escravo piauiense, também ex-combatente, casado com paraguaia.

RECEBIDO EM: 24/11/2015

APROVADO PARA PUBLICAÇÃO: 28/11/2015 